\title{
Carbon Emissions Scenario Prediction of the Thermal Power Industry in the Beijing-Tianjin-Hebei Region Based on a Back Propagation Neural Network Optimized by an Improved Particle Swarm Optimization Algorithm
}

\author{
Jianguo Zhou, Shijuan Du*, Jianfeng Shi, Fengtao Guang \\ Department of Economics and Management, North China Electric Power University, \\ 689 Huadian Road, Baoding 071003, China
}

Received: 10 December 2016

Accepted: 8 February 2017

\begin{abstract}
Rapid economic growth in the Beijing-Tianjin-Hebei region has been accompanied by a dramatic increase in carbon emissions. Therefore, a precise study of forecasting carbon emissions is important as regards curbing them. To identify the influence factors of carbon emissions and effectively predict carbon emissions under the three different GDP growth rate scenarios in the Beijing-Tianjin-Hebei thermal power industry, we employed a combination of the improved particle swarm optimization-back propagation algorithm (IPSO-BP) with scenario prediction. The results are as follows:

1) The influencing degree of carbon emissions factors from strong to weak are the installed capacity of thermal power, thermal power generation, urbanization rate, GDP, and utilization ratio of units (with grey correlation degrees of $0.9262,0.9247,0.8683,0.8082$, and 0.7704 , respectively).

2) Compared with the BP neural network, it is testified that using the IPSO-BP neural network model with an annual average relative error of $2.53 \%$, while the prediction precision of BP neural network is $5.07 \%$. Besides, the number of iterations to achieve the optimal solution is approximately reduced by $33 \%$.

3) GDP is the contributor to the increment of carbon emissions of the power industry, whereby GDP growth rate can be reduced appropriately to curb carbon emissions, avoiding excessive pursuit of economic growth.
\end{abstract}

Keywords: carbon emissions, IPSO-BP neural network model, scenario prediction, Beijing-TianjinHebei thermal power industry

*e-mail: 1528956034@qq.com 


\section{Introduction}

The climate change problem caused by greenhouse gas emissions has become a global issue of common concern today. A recent study shows that carbon emissions affect thermal comfort and lead to climate change problems [1], thus affecting natural areas and coastal areas [2-4]. As the world's largest emitter of greenhouse gases, China has been taking active measures to cope with climate change. At the 2009 Copenhagen Summit, the Chinese government committed to reduce its national carbon emissions carbon intensity by $40-45 \%$ over the period $2005-20$ [5]. The power industry mainly adopts coal-fired power generation and is the leading source of carbon emissions across China. To achieve the fixed goal, the power industry is supposed to shoulder a big responsibility. Accompanied with the implementation of the Beijing-Tianjin-Hebei regional integration strategy, the economy of the BeijingTianjin-Hebei region has developed rapidly. In December 2016, the Beijing-Tianjin-Hebei region and surrounding areas account for about half of the total coal consumption of China. Besides, the installed capacity of thermal power accounts for $35 \%$ of that in China, according to Zhao Yingmin, vice minister of environmental protection. So it has become the area with the most energy consumption and carbon emissions. Accordingly, the inhibition of carbon emissions is a paramount way to protect the environment, thus research on carbon emissions from the thermal power industry in the Beijing-Tianjin-Hebei region seems increasingly necessary and important.

There are many kinds of forecasting methods for predicting carbon emissions - specifically accordance with the different classification criteria that may fall into various patterns. Based on the number of methods adopted, all forecasting methods can be divided into single forecasting and combined forecasting methods. The single forecasting method has grey prediction [6], linear regression [7], discriminant analysis [8], time series prediction [9], support vector machine [10], BP neural network [11], and so on. Although the single forecasting method has the advantage of ease of use and ease of understanding, the shortcomings of its narrow applicable range and low accuracy limit its further application. Due to the limitations of the single forecasting method, the combined forecasting method is imported for further analysis and forecast. The combined forecasting method is a popular research topic that combines various technologies and single forecasting methods, such as [1215]. Besides that, according to whether or not to consider the impact of factors, existing forecasting methods can be classified into two types. One based on the change trend of previous data ignores the factors that affect carbon emissions, such as grey prediction [16] and time series prediction [17]. Conversely, the other takes into account the influence factors related to carbon emissions, such as scenario prediction [18], the STIRPAT model [19], and the BP neural network.

In the present period, there are a lot of studies for carbon emissions including indoor and outdoor, especially urban cities and parks [20-23]. Besides, the forecasting methods of carbon emissions mainly encompass scenario prediction, the STIRPAT model, and time series prediction. Time series prediction highlights the effect of time sequence factor while other factors tend to be ignored. Besides, it is applicable only to the short-term prediction. The STIRPAT model takes into account the influence factors on carbon emissions owing to the fixed quantitative calculation, and it is limited in the prediction error caused by a multicollinearity of influencing factors. Given carbon emissions affected by many factors, scenario prediction has become the mainstream of forecasting carbon emissions [24]. By the analysis of environmental effect and exterior factors affecting research subjects, the whole process of scenario prediction is to simulate different kinds of possible scenarios and predict future prospects; however, there exist large errors in scenario prediction.

From the previous literature, it can be concluded that there are some drawbacks to the existing single forecasting methods, and the combined forecasting methods in predicting carbon emissions have been widely used. Moreover, the comprehensive research findings mainly concentrate on the level of countries or regions around the world, while research on carbon emissions in the Beijing-Tianjin-Hebei thermal power industry appears to be not enough. Furthermore, existing literature has short time spans. For remedying the shortcomings of existing methods and study objects, this paper combines the improved particle swarm optimization-back propagation algorithm (IPSO-BP) with scenario prediction to predict carbon emissions under the three different GDP growth rate scenarios in the Beijing-Tianjin-Hebei thermal power industry during 2015 to 2020 . The BP neural network has the ability of high fault tolerance and self-adaptability for unstructured and clear irregular data and has been proven to predict carbon emissions [25]. Besides, the main objectives of this paper are:

1. To identify and select the major influence factors pertaining to carbon emissions by the Beijing-TianjinHebei thermal power industry by grey relation analysis.

2. To testify to the performance of the improved model while the IPSO-BP neural network model and BP neural network are tested along with a comparative analysis.

3. To predict the carbon emissions under the three different GDP growth rate scenarios in the BeijingTianjin-Hebei thermal power industry from the perspective of the combination of the IPSO-BP neural network model and scenario prediction.

4. To provide policy recommendations for the lowcarbon development of the Beijing-Tianjin-Hebei thermal power industry.

The rest of this study is constructed as follows: Firstly, based on the analysis of influence factors of carbon emissions by GRA, Section 2 describes the model and data used for empirical analysis. Secondly, Section 3 illustrates and discusses the empirical results. Finally, conclusions and policy implications are presented in Section 4. 


\section{Material and Methods}

\section{Date Source and Estimation}

With no official data of carbon emissions releases currently scheduled from the Beijing-Tianjin-Hebei thermal power industry, there is a need to calculate energy-related carbon emissions in this paper. At present, it should be noted that carbon emissions of the thermal power industry only involve that of fossil energy consumption dominated by coal in the process of thermal power generation [26]. Take the particularity of the power industry into consideration and on the basis of the industry carbon emissions formula proposed by Li Hong and Ya Kun [27], the specific calculation formula can be simplified as follows:

$$
c_{j}=\sum_{i=1}^{n} p_{j i} * \xi_{i} * k_{i}
$$

... where $c_{j}$ is total carbon emissions of industry $j$ (represents the thermal power industry); $i$ denotes fossil energy types, involving raw coal, cleaned coal, briquettes, and other types of coal, oil and its products, and gas and its products; $p_{j i}$ refers to the consumption of $i$ th fossil energy; $\zeta_{i}$ is the conversion coefficient of fossil energy i to standard coal; and $k_{i}$ is the carbon emission coefficient of fossil energy $i$. Noticeably, standard coal coefficient and carbon emission coefficients adopt the recommended value of IPCC [28]. Moreover, In order to intuitively observe the variation trend of carbon emissions, the amount of carbon emissions are shown in Fig. 1 based on Equation (1).

The total GDP of Beijing-Tianjin-Hebei is derived from the China Energy Statistical Yearbook, and it is converted to 2005 prices to eliminate inflation. Furthermore, thermal power generation and installed capacity of thermal power are total values of the thermal power industry in three

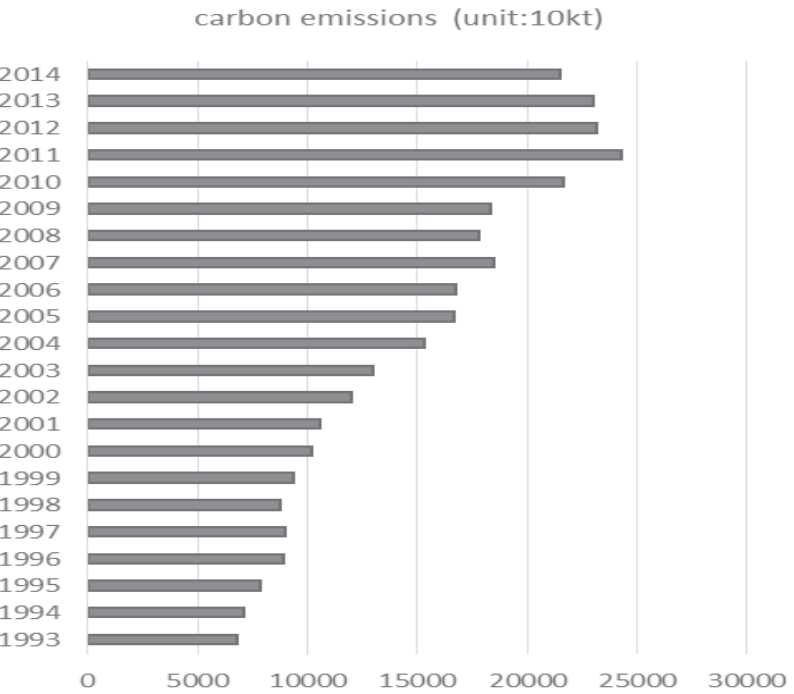

Fig. 1. Carbon emissions of the thermal power industry in Beijing-Tianjin-Hebei from 1993 to 2014. provinces and cities, while utilization ratio of units is the average, and the data are all collected from the China Electric Power Yearbook (1995-2015).Other relevant data come from the Beijing Statistical Yearbook (1994-2015), Tianjin Statistical Yearbook (1994-2015), and Hebei Economics Yearbook (1994-2015).

\section{Grey Relation Analysis}

Given the numerous related factors of carbon emissions, the secondary factor can be ignored to make the algorithm more concise and effective. In reference to existing research results [29-30] and the characteristics of the thermal power industry, the influence factors of the carbon emissions in this paper mainly consist of thermal power generation, urbanization rate, GDP, installed capacity of thermal power, and the utilization ratio of units. Among these factors, urbanization rate is indicated with the ratio between urban population and total resident population and utilization ratio of units can be expressed as the ratio of units operating hours to total hours per year. Then the grey relational analysis method is adopted to explore the relationship between the five influence factors and carbon emissions.

The grey relation analysis is to illustrate the development trend of a system quantitatively and compare the statistical data of time series in the system, and the grey correlation degree can be obtained to reflect the correlation between reference sequence and comparison sequence [31]. It should be noted that the greater the grey correlation degree, the closer they are. Grey relation analysis is indispensable for probing the relationships between research objects with imperfect information, inadequate data, and unclear internal connections [32]. In the GRA process, the initial data from evaluation objects should first be standardized, and then the grey correlation degree between the comparison sequence and the reference sequence can be calculated. In this paper, the reference consequence is carbon emissions, while thermal power generation, urbanization rate, GDP, installed capacity of thermal power, and utilization ratio of units are selected to be the comparison sequences.

\section{A Back Propagation Neural Network}

A back propagation (BP) neural network is a kind of multilayer feed-forward network with information forward propagation and error back propagation as proposed by a team of scientists led by Rumelhart and McCelland in 1986. In forward propagation, the information from the input layer to the output layer via hidden layer is calculated layer by layer. In addition, the neuron state of each layer is only directly affected by the neuron state of the upper layer. If the output value is inconsistent with the desired output, the network will turn into the state of backward propagation, then the weights and thresholds of the neural network are constantly adjusted by the BP neural network to reduce the error and until the desired output is achieved. Furthermore, the typical network is a 
three-layer network that involves the input network, the output network, and the hidden network [33]. However, the BP neural network randomly set the connection weights and thresholds. Consequently, the improper choice directly affects convergence effect and the ultimate steady state, which brings about a local optimum easily. Generally speaking, the appropriate values can be determined by BP neural network through continuous training, which leads to the increment of time complexity and the phenomena of over-fitting, and the prediction results may fail to be accurate [34]. IPSO is introduced to overcome the above shortcomings by optimizing the connection weights and threshold of the BP neural network.

\section{An Improved Particle Swarm Optimization Algorithm (IPSO)}

The particle swarm optimization (PSO) algorithm is a classical artificial intelligence algorithm proposed by Kenney and Eberhart, inspired by the foraging behavior of bird flocks [35]. PSO can be implemented with simple principles and a deep intelligent background, as well as having maximum strength in dealing with complex problems. However, PSO is prone to appearing premature convergence and easily getting trapped in a local optimum. In the basic PSO algorithm, assume that the search space is a D-dimensional space and the population is composed of a particle swarm $x_{i}=\left(x_{1}, x_{2} \ldots . . x_{n}\right)$, while the number of particle swarm is $n$; the particle $i$ of a swarm by a D-dimensional space can be represented by $x_{i}=\left(x_{i 1}, x_{i 2} \ldots \ldots x_{i D}\right)$; the velocity of $i$ th particle is $\mathrm{V}_{i}=\left(v_{i 1}, v_{i 2} \ldots \ldots v_{i D}\right)$, which involves direction and distance, determining the search capability of each particle in search space. The optimal position that the $i$ th particle has achieved so far is $P_{i}=\left(p_{i 1}, p_{i 2}, p_{i 3} \ldots . . . p_{i D}\right)$ and the corresponding value is called Pbest, namely individual extremum, while the $p$ denotes the positions that the particles have achieved. Likewise, the best position in the whole particle swarm that the $i$ th particle has achieved during the current search is $g_{i}=\left(g_{i 1}, g_{i 2}, g_{i 3} \ldots . . g_{i D}\right)$ and Gbest is called global extremum, while the $g$ has the same meaning of $p$ [36].

PSO randomly initializes a particle swarm and the velocity of each particle, and each particle updates its velocity and position by means of dynamic tracking of Pbest and Gbest [37]. Besides, the inertia weight, which can be adjusted, plays an important role in balancing the relationship between global and local search capabilities at each iteration. The liner decreasing inertia weight (LDW) proposed by Shi [38] was widely adopted in application, and the inertia weight and update formula of particles can be presented as follows:

$$
\begin{gathered}
w=w_{\max }-\frac{t^{*}\left(w_{\max }-w_{\min }\right)}{t_{\max }} \\
v_{i D}=w v_{i D}+c_{1} r_{1}\left(p_{i D}-x_{i D}\right)+c_{2} r_{2}\left(g_{i D}-x_{i D}\right) \\
x_{i d}=x_{i d}+v_{i d}
\end{gathered}
$$

...where $w$ is inertia weight coefficient, hence $w_{\max }$ and $w_{\min }$ refer to the maximum and minimum inertia weight, respectively, which are suggested to be 0.9 and $0.4 ; t$ denotes the current iteration number, accordingly $t_{\max }$ is the maximum iteration number; $c_{1}$ and $c_{2}$ are learning factors, generally $c_{1}=c_{2}=2$ were used, while $r_{1}$ and $r_{2}$ usually take random numbers in $[0,1]$; if $v_{i D}>V_{\max }$ it indicates $v_{i D}=V_{\max }$, meanwhile, if $v_{i D}>-V_{\max }$ it indicates $v_{i D}=-V_{\max }$, thereby the velocity of particles are often limited to $\left[-V_{\max }, V_{\max }\right]$, and denotes the maximum velocity of all particles.

The inertia weight is an important parameter affecting the performance of PSO algorithm, and search and convergence abilities can be effectively controlled. Although LDW strategy has been accepted by the vast majority of researchers, it possesses some defects in the current practical application. In the PSO initial of operation, if the desired output is reached, it's hoped that faster convergence to the target can be achieved, whereas the linearly decreasing of $w$ reduces the convergence speed. In later periods, with the continuous reduction of $w$, the particle diversity and the global search ability will decline, which often results in a local optimum. Therefore, this paper utilizes the IPSO algorithm to compensate its defects. Selective mutation strategy inspired from genetic algorithm (GA) is introduced in PSO to overcome the aforementioned shortcomings [39]. As a consequence of selective mutation strategy, the position variables of particles are reinitialized with the preset probability, thus the diversity of particles can be increased and the search space of population in the iteration procedure can be expanded. Finally, the optimal result will be obtained. The improved inertia weight $w$ can be expressed as:

$$
w=\left(w_{\max }-w_{\min }\right) *\left[\frac{\left(t_{\max }-t\right)}{t_{\max }}\right]^{h}+w_{\min }
$$

... where $h$ is the nonlinear modulation index, equal to 1.2; moreover, other parameters and variables represent the same meaning as Eq.(2).

\section{IPSO-BP Neural Network Model}

In view of the defects of the BP neural network algorithm, this paper utilized the IPSO algorithm to obtain the optimal particle, which can optimize the link weights and threshold value of the BP neural network. Besides, the learning capability, convergence rate, and global optimization capability of this model will be enhanced. The specific flow chart of the IPSO-BP algorithm is shown in Fig. 2.

\section{The Scenario Prediction Method}

Scenario prediction is a kind of scientific, effective, and systematic forecasting method. Based on the scenario description, the scenario prediction is to conceive the future possible scenarios through the identification and 


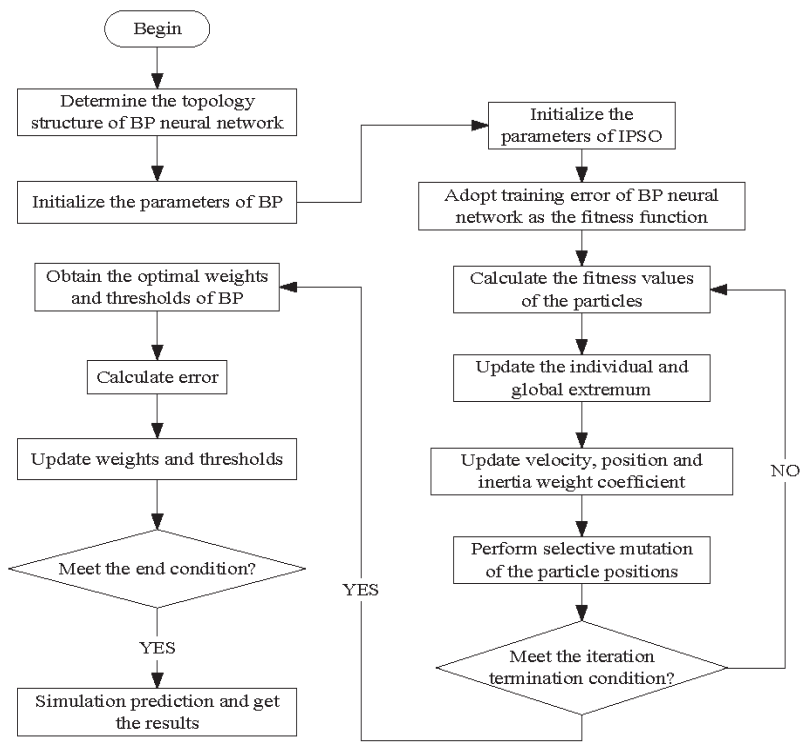

Fig. 2. Flow chart of the IPSO-BP algorithm.

analysis of external influence factors [40]. The biggest advantage of this method is that the future development trend of the predicting subjects will be clear and intuitive. Meanwhile, excessively high or low evaluation results can be avoided. In addition, the characteristics of the scenario prediction method are mainly described as follows:

1. The development trend of forecasting objects remains highly uncertain, accordingly, there exist various of forecasting results.

2. Taking the people's subjective initiative into consideration, the willingness and ideas of policymakers are indispensable parts of scenario prediction.

3. In the process of scenario prediction, quantitative analysis is combined with a large number of qualitative analysis, which is quite different from the quantitative analysis in the trend extrapolation method.

4. The scenario prediction method is a kind of thinking method involving multi-discipline and multi-field. The adopted technology and methods are mainly derived from other related subjects, which makes the scenario prediction method possess the characteristics of psychology, future studies, and statistics [41].

\section{Results and Discussion}

\section{The Grey Relation Analysis Results}

According to the GRA results, the influence of carbon emissions factors from strong to weak are: installed capacity of thermal power, thermal power generation, urbanization rate, GDP, and utilization ratio of units. In addition, it can be seen that the correlation degree between the comparison sequences and the reference sequence are all over the critical value of 0.6 , which indicates that there exists a significant correlation between the selected influence factors and carbon emissions [42]. Therefore, the results indicate that the selected influence factors have a significant correlation with carbon emissions, and they are well suitable for further prediction and study. It is believed that these selected influence factors can be the input indicators of the model to predict the carbon emissions. Furthermore, it is of great significance to take effective measures for the relevant government authorities to curb carbon emissions. Specifically, the grey correlation degrees are presented as follows:

$$
\begin{gathered}
r_{01}=0.9247 \quad r_{02}=0.8682 \\
r_{03}=0.8086 \quad r_{04}=0.9296 \quad r_{05}=0.7704
\end{gathered}
$$

...where $r_{01}$ denotes the correlation degree between the thermal power generation and carbon emissions; $r_{02}$ denotes the correlation degree between urbanization rate and carbon emissions; $r_{03}$ refers to the correlation degree between GDP and carbon emissions; $r_{04}$ refers to the correlation degree between installed capacity of thermal power and carbon emissions; and $r_{05}$ is the correlation degree between utilization ratio of units and carbon emissions.

\section{The Inspection Results of the IPSO-BP Neural Network Model}

Based on MATLAB programming, this paper selected the data of the thermal power industry in the BeijingTianjin-Hebei region during the period 1993-2009 as training samples, but the remaining data during the period of 2010-2014 are test samples. To testify to the performance of the improved model, the IPSO-BP neural network model and BP neural network are tested respectively. The input indicators of the two models are thermal power generation, urbanization rate, GDP, installed capacity of thermal power, and utilization ratio of units, while the output indicator is carbon emissions from the thermal power industry. In the comparison of training results, the BP neural network can achieve the highest prediction accuracy when complying with the following conditions. The maximal algebra of network iteration is 120 times; meanwhile, the error precision and the learning rate are set to 0.0001 and 0.1 , respectively. In the IPSO algorithm, the number of the population is 40 , the maximal algebra of iteration is 80 times, and the mutation probability is set to be 0.9 . Moreover, the range of search space is $[-3,3]$ and velocity of swarm particle range is limited to a value within $[-1,1]$. In addition, the final network structure is designed as 5-8-1 - in other words, the hidden layer includes eight nodes.

As shown in Fig. 3 and Table1, the two models can better reflect the developing trend of carbon emissions during the time slot of 2010-14, and it's believed that the two models are well fitted to predict carbon emissions. However, there are some differences in certain aspects. In predictive accuracy, the annual average relative error of IPSO-BP neural network is $2.53 \%$, compared with $5.07 \%$ for the BP neural network. Thus it can be seen that the 


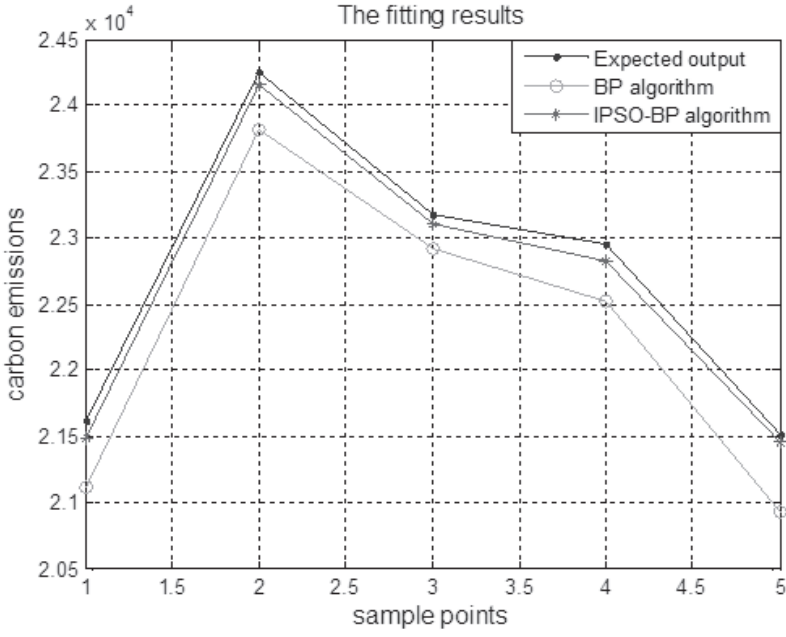

Fig. 3. Prediction results of carbon emissions from the BeijingTianjin-Hebei thermal power industry, 2010-14.

IPSO-BP neural network significantly improves predicting precision. In convergence rate, the iteration number of IPSO-BP neural network is 80 times, while the other is 120 . Obviously, it can be concluded that the IPSO-BP neural network is more effective in improving the convergence rate of the network. Overall, the results indicate that the IPSO-BP neural network model takes full advantage of the global search capability of the IPSO algorithm and local search capability of the BP neural network, so the fitting accuracy and convergence rate of this model are improved notably; besides, this paper indicates the fact that the IPSO$\mathrm{BP}$ algorithm has superiority over the $\mathrm{BP}$ algorithm and is an ideal method for the prediction of carbon emissions based on the comparative analysis of two models.

\section{Scenario Prediction Results for Influence Factors}

\section{Scenario Prediction for GDP}

In compliance with the "Collaborative Development Planning of Beijing, Tianjin, and Hebei Province" and the " $13^{\text {th }}$ Five-Year Plan for the Beijing, Tianjin, and Hebei Province," the province should maintain an annual average growth rate of $6.5 \%, 8.5 \%$, and $7 \%$, respectively.
Accordingly, the government requirements can be set as policy scenario. Besides that, in reference to the scenario prediction for GDP proposed by Song and Zhang [43], this paper adopts a low-speed scenario and high-speed scenario to set the value of GDP during 2015 to 2020, with an annual average growth rate of $6.4 \%$ and $8 \%$, respectively. By calculation, the specific scenario setting results are shown in Table 2.

\section{The Scenario Prediction for Urbanization Rate}

According to the data released by the national bureau of statistics, the urbanization rate of Beijing-TianjinHebei Province is $62.08 \%$ by calculation. Based on the requirements of the Tianjin urban master plan (2005-20), total population is 1,350 million, while the urban population is up to 1,210 million, and the urbanization rate reaches approximately $90 \%$ in Tianjin by the end of 2020 . Similarly, in accordance with the Beijing urban master plan (2004-20), the urbanization rate could be as high as $90 \%$ in Beijing by the end of 2020 . In light of "new urbanization and urban and rural areas in Hebei province and urban planning (2016-20) requirements promulgated by the Hebei provincial government, the urbanization rate standard for Hebei Province is approximately $53 \%$ by the end of 2017, while in 2020 the standard of $60 \%$ can be achieved. According to the above requirements, the annual urbanization growth rate of the Beijing-TianjinHebei region is set to $5.2 \%$ by calculation. Therefore, the urbanization rate of the Beijing-Tianjin-Hebei region can be set to $65.31 \%, 68.70 \%, 72.28 \%, 76.04 \%$, and $80.03 \%$ from 2015 to 2020 , respectively.

\section{The Prediction for Utilization Ratio of Units}

During the period of 1993-2014, using the raw data of utilization ratio of units from the thermal power industry in the Beijing-Tianjin-Hebei region for linear fitting, and the results demonstrate that the variation trend is approved by significance testing. Based on this trend, the variation trend can be represented by $\alpha^{93-14}$ through computation, equal to $0.28 \%$, and the intercept is 6.26 . According to the above computation and analysis, utilization ratio of

Table 1. Prediction results of carbon emissions in the Beijing-Tianjin-Hebei thermal power industry from 2010 to 2014.

\begin{tabular}{|c|c|c|c|c|c|}
\hline Year & Actual values & $\begin{array}{c}\text { Predictive values } \\
\text { (IPSO-BP) }\end{array}$ & $\begin{array}{c}\text { Relative error } \\
\text { (IPSO-BP) }\end{array}$ & $\begin{array}{c}\text { Predictive values } \\
\text { (BP) }\end{array}$ & $\begin{array}{c}\text { Relative } \\
\text { Error (BP) }\end{array}$ \\
\hline 2010 & $21,619.06$ & $20,511.0570$ & 0.0513 & $21,121.8216$ & 0.0230 \\
\hline 2011 & $24,244.95$ & $23,617.9759$ & 0.0259 & $23,961.2841$ & 0.0117 \\
\hline 2012 & $23,167.29$ & $21,916.2545$ & 0.0540 & $22,518.6059$ & 0.0280 \\
\hline 2013 & $22,954.63$ & $21,623.2633$ & 0.0580 & $21,921.6717$ & 0.0450 \\
\hline 2014 & $21,511.90$ & $20,123.5432$ & 0.0645 & $21,511.9000$ & 0.0186 \\
\hline Mean values & - & - & 0.0507 & - & 0.0253 \\
\hline
\end{tabular}


Table 2. Scenario predictive values of GDP in Beijing-TianjinHebei from 2015 to 2020.

\begin{tabular}{|c|c|c|c|}
\hline Year & $\begin{array}{c}\text { Low-speed } \\
\text { scenario }\end{array}$ & $\begin{array}{c}\text { Policy } \\
\text { scenario }\end{array}$ & $\begin{array}{c}\text { High-speed } \\
\text { scenario }\end{array}$ \\
\hline 2015 & $57,531.87$ & $57,978.67$ & $58,397.01$ \\
\hline 2016 & $61,213.91$ & $62,171.55$ & $63,068.78$ \\
\hline 2017 & $65,131.60$ & $66,671.06$ & $68,114.28$ \\
\hline 2018 & $69,300.03$ & $71,499.91$ & $73,563.42$ \\
\hline 2019 & $73,735.23$ & $76,682.47$ & $79,448.49$ \\
\hline 2020 & $78,454.28$ & $82,244.98$ & $85,804.37$ \\
\hline
\end{tabular}

Table 3. Index predictive values in Beijing-Tianjin-Hebei from 2015 to 2020.

\begin{tabular}{|c|c|c|}
\hline Year & $\begin{array}{c}\text { Thermal power } \\
\text { industry } \\
\text { (billion Kwh) }\end{array}$ & $\begin{array}{c}\text { Installed capacity of } \\
\text { thermal power } \\
\text { (million Kw) }\end{array}$ \\
\hline 2015 & $3,905.9$ & $6,810.0$ \\
\hline 2016 & $4,211.7$ & $7,219.0$ \\
\hline 2017 & $4,541.5$ & $7,782.5$ \\
\hline 2018 & $4,897.1$ & $8,390.0$ \\
\hline 2019 & $5,280.5$ & $9,046.0$ \\
\hline 2020 & $5,694.0$ & $9,752.0$ \\
\hline
\end{tabular}

units of thermal power industry in the Beijing-TianjinHebei region can be set to $0.5777,0.5748,0.5720,0.5692$, 0.5664 , and 0.5635 .

\section{The Prediction for Thermal Power Generation and Installed Capacity of Thermal Power}

As the frequently used grey model, GM $(1,1)$ is particularly available to the small sample data owing to the advantage of ease of use and higher prediction accuracy. Consequently, the prediction of thermal power generation and installed capacity of thermal power can be performed by programming on the basis of GM $(1,1)$. The specific prediction results are shown in Table 3.

\section{Scenario Prediction Results}

Based on the aforementioned prediction results of influence factors, we can obtain the values of five input indexes during the period 2015-20, then apply the welltrained IPSO-BP neural network model to forecast the carbon emissions from the thermal power industry in the Beijing-Tianjin-Hebei region under three different scenarios: low-speed, policy, and high-speed.

As shown in Table 4 and Fig. 4, it is believed that carbon emissions from the thermal power industry are always on the rise under different scenarios from 2015 to 2020 . In the low-speed scenario, the carbon emissions
Table 4. The scenario predictive values of carbon emissions in Beijing-Tianjin-Hebei from 2015 to 2020

\begin{tabular}{|c|c|c|c|}
\hline Year & $\begin{array}{c}\text { Low-speed } \\
\text { scenario }\end{array}$ & $\begin{array}{c}\text { Policy } \\
\text { scenario }\end{array}$ & $\begin{array}{c}\text { High-speed } \\
\text { scenario }\end{array}$ \\
\hline 2015 & 22,690 & 22,321 & 23,895 \\
\hline 2016 & 22,720 & 23,709 & 24,169 \\
\hline 2017 & 23,045 & 23,926 & 24,786 \\
\hline 2018 & 23,474 & 24,044 & 25,076 \\
\hline 2019 & 23,534 & 24,125 & 25,391 \\
\hline 2020 & 23,754 & 24,637 & 25,595 \\
\hline
\end{tabular}

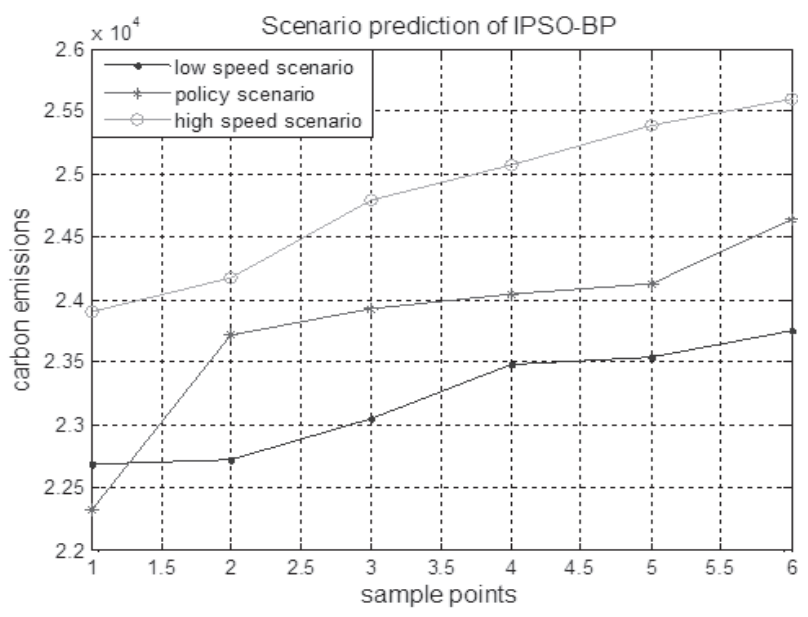

Fig. 4. Scenario prediction results of the IPSO-BP neural network model.

will achieve 23,754 million tons in 2020, increased more than $10.42 \%$ in 2014 . In the high-speed scenario, the carbon emissions will increase from 21,512 million tons (in 2014 level) to 25,595 million tons in 2020 , and the growth rate will be $18.99 \%$ compared with the value in 2014. In the policy scenario, the amount of emissions will reach 24,637 million tons, up 14.53\% from 2014 . As stated above, although the carbon emissions in the low-speed scenario are relatively small compared to the other scenarios, it can't meet the requirements of the 13th Five-Year Plan for Beijing, Tianjin, and Hebei Province." Furthermore, although the growth rate of GDP in the high-speed scenario is the fastest of the three scenarios, it is estimated that the carbon emissions from thermal power industry are the largest, which is not conducive to the protection of the environment. In addition, the growth rate of GDP in the policy scenario can be achieved effectively. Meanwhile, it's favorable to realize the carbon emissions reduction of the strategic target in and meet the requirement of environmental protection in the Beijing-Tianjin-Hebei region. The results indicate that GDP increases rapidly accompanied by the greater increments of carbon emissions, which indicates the fact that GDP is the positive driving force for the increase of 
carbon emissions, and thereby the GDP growth rate can be reduced appropriately, avoiding excessive pursuit of economic growth.

\section{Conclusions}

\section{Major Conclusions}

Along with the rapid development of the thermal power industry in the Beijing-Tianjin-Hebei region, the sharp increase of carbon emissions brings about severe challenges for environmental protection. To identify the influence factors of carbon emissions, verify the validity of the proposed model, and effectively predict carbon emissions, this paper combines the IPSO-BP neural network model with scenario prediction to predict carbon emissions under the three different GDP growth rate scenarios in the Beijing-Tianjin-Hebei thermal power industry during 2015 to 2020 . Firstly, given that there is no official data of carbon emissions, the recommended IPCC values are used to calculate energy-related carbon emissions. Secondly, the grey relation analysis is utilized to delve into the influence factors of carbon emissions in the power industry. Thirdly, the combination of IPSO-BP neural network and scenario prediction is adopted to predict carbon emissions from the thermal power industry in the region under different scenarios. The main conclusions drawn by this study are:

1. Based on the grey relation analysis results, the influence of carbon emissions factors from strong to weak are: installed capacity of thermal power, thermal power generation, urbanization rate, GDP, and utilization ratio of units. The grey correlation degrees are 0.9262 , $0.9247,0.8683,0.8082$, and 0.7704 , respectively.

2. In this paper, the relevant data from the thermal power industry in the Beijing-Tianjin-Hebei region during 1993 to 2014 were selected for empirical analysis. Compared with the BP neural network, it is testified that using the IPSO-BP neural network model with an annual average relative error of $2.53 \%$, and the accuracy of predicting is elevated by $2.54 \%$. Besides, the number of iterations to achieve the optimal solution is reduced by around 33\%.

3. This paper combined the IPSO-BP neural network model with scenario prediction to predict the carbon emissions from the thermal power industry in the Beijing-Tianjin-Hebei region during the period of 2015-2020. In policy scenario, the carbon emissions from the thermal power industry in the region will reach $22,321,23,709,23,936,24,044,24,125$, and 24,637 million tons, which achieves the goal of the 13th Five-Year Plan for the province, and it is conducive to environmental protection.

\section{Policy Implications}

Based on the grey analysis results and scenario prediction results, several policy implications are recommended to mitigate carbon emissions in the BeijingTianjin-Hebei thermal power industry:

1. The improvement of the comprehensive utilization efficiency of energy and appropriate reduction of the GDP growth rate can effectively inhibit the carbon emissions of the thermal power industry. On the one hand, the government should focus on exploiting, importing, and popularizing the energy-related technologies to enhance the utilization efficiency of energy in the region, such as integrated gasification combined cycle (IGCC) and UHV transmission technology. Use advanced technology to optimize and upgrade the existing thermal power units, and the utilization hydropower units should be strengthened; on the other hand, GDP is the main driver of increasing carbon emissions. Therefore, the GDP growth rate can be reduced appropriately to achieve low-carbon economy in the Beijing-Tianjin-Hebei thermal power industry.

2. The utilization of clean energy is an effective approach to achieve carbon emissions reduction in the region. Accompanied by the continuous increase of installed capacity of thermal power, the consumption of high carbon energy dominated by coal also experiences rapid growth. To address this challenge, the continuous implementation of the policy "encouraging large projects and discouraging small energy-inefficient power plants" should be kept. Coal utilization efficiency and heat efficiency should be enhanced. Conversely, coal consumption for power generation should be reduced. Meanwhile, intensify the efforts to explore clean and renewable energy resources in power generation, such as utilizing the wind, solar resources, and biomass energy.

3. Transferring the electricity from other provinces to the region is a crucial way to relieve the stress of production and carbon emissions of the thermal power industry. The rapid development of thermal power industry has contributed to a dramatic rise in power generation and carbon emissions. To counter this, the requirements of "Capital power supply security relies on the BeijingTianjin-North Hebei grid, and the power supply security of Beijing-Tianjin-North Hebei grid relies on the North China power grid" are supposed to be kept. Enhance the ability of diverting power supply from Shanxi in northeastern China as a compensation for the power deficit. Moreover, speed up the construction of power transmission facilities, cable channels, and smart grid and losses of transmission and distribution should be minimized, and then the diminution of carbon emissions can be achieved.

In conclusion, this study contributes to previous research on the prediction of carbon emissions from the thermal power industry in the Beijing-Tianjin-Hebei region, and our main contribution here is twofold. Firstly, this paper indicates the fact that the IPSO-BP neural network model is superior to the BP network and is an ideal method for predicting carbon emissions. Secondly, the IPSO-BP neural network model combined with scenario 
prediction is employed to predict carbon emissions from the Beijing-Tianjin-Hebei thermal power industry, and some corresponding policies are recommended for the policymakers. It is hoped that future studies should extend this study, such as quantifying and construing the interaction between influencing factors and carbon emissions from the thermal power industry specifically.

\section{Acknowledgements}

The research was supported by the National Natural Science Foundation of China (NSFC) (grant No. 71471061).

\section{References}

1. CETIN M., ADIGUZEL F., KAYA O., SAHAP A. Mapping of bioclimatic comfort for potential planning using GIS in Aydin, Environment Development \& Sustainability, 1, 2016.

2. CETIN M., SEVIK H. Assessing Potential Areas of Ecotourism through a Case Study in Ilgaz Mountain National Park, Tourism - From Empirical Research Towards Practical Application, 2016.

3. CETIN M. Sustainability of Urban Coastal Area Management: A Case Study on Cide. 35 (7), 527, 2016.

4. KAYA L.G., CETIN M., DOYGUN H. A Holistic Approach in Analyzing the Landscape Potential: Porsuk Dam Lake and Its Environs, Turkey, Fresenius Environmental Bulletin, 18 (8), 1525, 2009.

5. YI B.W., XU J. H, YING F. Determining factors and diverse scenarios of $\mathrm{CO}_{2}$ emissions intensity reduction to achieve the $40-45 \%$ target by 2020 in China - a historical and prospective analysis for the period 2005-2020, Journal of Cleaner Production, 122, 87, 2016

6. ZHAO A.W., LI D. Grey Forecast of China's Carbon Dioxide Emissions, Mathematics in Practice and Theory, 42 (4), 61, 2012

7. SHU Y., LAM N.S.N. Spatial disaggregation of carbon dioxide emissions from road traffic based on multiple linear regression model, Atmospheric Environment, 45 (3), 634, 2011.

8. NAIK M.K., PANDA R. A novel adaptive cuckoo search algorithm for intrinsic discriminant analysis based face recognition, Applied Soft Computing, 38 (C), 661, 2016.

9. CHOI K.H., ANG B.W. A time-series analysis of energyrelated carbon emissions in Korea, Energy Policy, 29 (13), $1155,2001$.

10. SUN W., LIANG Y., XU Y. Application of carbon emissions prediction using least squares support vector machine based on grid search, Wseas Transactions on Systems \& Control, $10(1), 95,2015$.

11. JI G.Y., DEPARTMENT P.E. Application of BP neural network model in the prediction of China's carbon emissions based on the grey correlation analysis, Mathematics in Practice \& Theory, 14, 243, 2014.

12. WU Z.X., SHI J. The influencing factor analysis and trend forecasting of Beijjing energy carbon emission based on STIRPAT and GM(1,1) model's, Chinese Journal of Management Science, (S2), 803, 2012.

13. ZHOU J.G., ZHANG X.G. Projections about Chinese $\mathrm{CO}_{2}$ emissions based on rough sets and gray support vector machine, China Environmental Science, 33 (12), 2157, 2013.
14. ZHANG F., YIN X.Q., DONG H.Z. Application of combination grey model in carbon emissions prediction in Shan Dong province, Environmental Monitoring \& Assessment, 33 (2), 147, 2015.

15. ZHAO C.B., MAO C.M. Forecast intensity of carbon emissions to China based on BP neural network and ARIMA combined model, Resources and Environment in the Yangtze Basin, 21 (6), 665, 2012.

16. PAO H.T., FU H.C., TSENG C.L. Forecasting of $\mathrm{CO}_{2}$, emissions, energy consumption and economic growth in China using an improved grey model, Energy, 40 (1), 400, 2012.

17. DOUCOURE B., AGBossou K., CARDEnAS A. Time series prediction using artificial wavelet neural network and multi-resolution analysis: Application to wind speed data, Renewable Energy, 92, 202, 2016.

18. YANG L., LIN B. Carbon dioxide-emission in China's power industry: Evidence and policy implications, Renewable \& Sustainable Energy Reviews, 60, 258, 2016.

19. WEN L., CAO Y. Factor decomposition analysis of China's energy-related $\mathrm{CO}_{2}$ emissions using STIRPAT model, Polish Journal of Environmental Studies, 24 (5), 2015.

20. CETIN M. A Change in the Amount of $\mathrm{CO}_{2}$ at the Center of the Examination Halls: Case Study of Turkey, Studies on Ethno-Medicine, 10 (2), 146, 2016.

21. CETIN M., SEVIK H. Measuring the Impact of Selected Plants on Indoor $\mathrm{CO}_{2}$ Concentrations, Polish Journal of Environmental Studies, 25 (3), 973, 2016.

22. SEVIK H., ÇETIN M., BELKAYALI N. Effects of Forests on Amounts of $\mathrm{CO}_{2}$ : Case Study of Kastamonu and Ilgaz Mountain National Parks, Polish Journal of Environmental Studies, 24 (1), 253, 2015.

23. SEVIK H., CETIN M. Effects of Water Stress on Seed Germination for Select Landscape Plants, Polish Journal of Environmental Studies, 24 (2), 689, 2015.

24. YIN Y., MIZOKAMI S., AIKAWA K. Compact development and energy consumption: Scenario analysis of urban structures based on behavior simulation, Applied Energy, 159, 449, 2015.

25. TIAN L., GAO L., XU P. The Evolutional Prediction Model of Carbon Emissions in China Based on BP Neural Network, International Journal of Nonlinear Science, 10, 1749, 2010.

26. HOU J.C., SHI D. Driving factors for the evolution of carbon dioxide emissions from electricity sector in China, China Industrial Economics, (6), 44, 2014.

27. LI HONG, YA KUN. The study on relationship between industrial carbon emission and the development of economy, Macroeconomics, 11, 46, 2012.

28. IPCC (Intergovernmental Panel on Climate Change), 2006. In: EGGLESTON H.S., BUENDIA L., MIWA K., NGARA T., TANABE K. (Eds.), 2006 IPCC Guidelines for National Greenhouse Gas Inventories, Prepared by the National Greenhouse Gas Inventories Programme. IGES, Japan.

29. YANG Q., LIU H.J. Regional Difference Decomposition and Influence Factors of China's Carbon Dioxide Emissions, The Journal of Quantitative \& Technical Economics, 5, 3649, 2012.

30. DU L.M. Impact Factors of China's Carbon Dioxide Emissions: Provincial Panel Data Analysis, South China Journal of Economics, 11, 20, 2010.

31. XU S.C., HE Z.X., LONG R.Y., CHEN H., HAN H. M., ZAANG W.W. Comparative analysis of the regional contributions to carbon emissions in China, Journal of Cleaner Production, 127, 406, 2016.

32. DENG J.L. Introduction to Grey system theory, Journal of Grey System, 1 (1), 1, 1989. 
33. REN C., AN N., WANG J., LI L., HU B. Optimal parameters selection for BP neural network based on particle swarm optimization: A case study of wind speed forecasting, Knowledge-Based Systems, 56 (3), 226, 2014.

34. ZHANG G.Y., HU Z. Improved BP neural network model and its stability analysis, Journal of Central South University (Science and Technology), 42 (1), 115, 2011.

35. KENNEDY J., EBERHART R.C. A discrete binary version of the particle swarm algorithm, In Proceedings of the 1997 IEEE International Conference on Computational Cybernetics and Simulation, Systems, Man, and Cybernetics, Orlando, FL, USA, 12-15 October 1997.

36. LI J., SHI J., LI J. Exploring Reduction Potential of Carbon Intensity Based on Back Propagation Neural Network and Scenario Analysis: A Case of Beijing, China, Energies, 9 (8), 2016.

37. SAYED M., GHARGHORY S.M., KAMAL H.A. Gain tuning PI controllers for boiler turbine unit using a new hybrid jump PSO, Journal of Electrical Systems \& Information Technology, 2 (1), 99, 2015.

38. SHI Y., EBERHART R.C. Parameter Selection in Particle Swarm Optimization, In International Conference on
Evolutionary Programming Vii, Spring-Verlag, London, UK, Volume 1447, 591,1998.

39. SUN W., Y X. Using a back propagation neural network based on improved particle swarm optimization to study the influential factors of carbon dioxide emissions in Hebei Province, China, Journal of Cleaner Production, 112, 1282, 2016.

40. YIN Y., MIZOKAMI S., AIKAWA K. Compact development and energy consumption: Scenario analysis of urban structures based on behavior simulation, Applied Energy, 159, 449, 2015.

41. WEN L., LIU Y. The peak value of carbon emissions in the Beijing-Tianjin-Hebei Region based on the STIRPAT model and scenario design, Polish Journal of Environment Studies, 25, 823, 2016.

42. LIU S.F., CAI H., YANG Y.J., YING C. Research progress of grey relational analysis model, Systems Engineering Theory \& Practice, 33, 2041, 2013.

43. SONG J.K., ZHANG Y. Scene prediction of China's carbon emissions based on BP neural network, Science technology and engineering, 11 (17), 4108, 2011. 